\title{
Immediate and sustained haemodynamic effects of prazosin during upright exercise in man
}

\author{
B SILKE, W G HENDRY, S H TAYLOR
}

\begin{abstract}
From University Department of Cardiovascular Studies and Department of Medical Cardiology, The General Infirmary, Leeds
\end{abstract}

SUMMARY To ascertain the immediate pharmacodynamic and long-term haemodynamic effects of prazosin in chronic ambulant heart failure, measurements were made during sitting, standing, and walking in 12 patients with severe ischaemic left ventricular failure before and after their first dose of prazosin $(2 \mathrm{mg})$ and in six of these patients after a further 12 weeks of sustained treatment $(2 \mathrm{mg}$ tds). When first added to treatment with digoxin and frusemide, prazosin was followed within an hour by substantial reductions in systemic arterial, pulmonary arterial, and pulmonary venous pressures in both postures at rest and also during walking. These changes were significantly attenuated after continued treatment. Cardiac output while sitting and standing at rest was reduced in both instances but the response to exercise was unchanged. The pharmacodynamic effects of prazosin in heart failure are explicable in terms of blockade of alpha ${ }_{1}$ adrenoceptors in arterial resistance and venous capacitance vessels augmented perhaps by lessening of reflex vasoconstriction secondary to the reduction in pulmonary venous pressure. The cause of the attenuation of the acute haemodynamic effects of the drug during sustained treatment is unknown.

Since the original demonstration by Majid et al. ${ }^{1}$ of the beneficial haemodynamic effects of vasodilator drugs in patients with severe heart failure, increasing interest has developed in their use both in acute and in chronic heart failure. The rationale of such treatment is physiologically sound and clinically attractive. ${ }^{2-4}$ Continued benefit of many vasodilator drugs in patients with ambulant heart failure has been difficult to establish, however. ${ }^{5}$ Prazosin, a selective alpha adrenoceptor antagonist, has been shown to result in haemodynamic improvement after acute administration to patients in severe heart failure, ${ }^{6-10}$ but claims of continued benefit during sustained treatment $^{11} 12$ have been disputed. ${ }^{13-15}$ The picture has also been confused by the fact that the majority of studies have been carried out at rest and in the supine posture, despite the fact that prazosin produces dose-dependent postural effects when first given to patients in heart failure. ${ }^{16}$ The following studies were therefore designed to define more exactly the effect of the drug on the circulation, both at the beginning of treatment and during its sustained administration, under conditions simulating some of the postural changes and exercise that ambulant heart failure patients normally undertake.

Received for publication 29 June 1981

\section{Method}

\section{PATIENTS}

Twelve men, aged 40 to 65 years, with chronic ischaemic heart failure (New York Heart Association, class III) were studied. All had suffered one or more myocardial infarctions three to 39 months before. In all patients the most recent event had been accompanied by acute left ventricular failure from which they had made a slow and incomplete recovery. All had been evaluated for coronary surgery but in no instance was this judged to be technically possible. Despite treatment with digoxin 0.25 to $0.5 \mathrm{mg}$ and frusemide 160 to $240 \mathrm{mg}$ daily they had remained largely incapacitated. At the time of these studies none was able to walk for more than a few minutes at a slow pace because of breathlessness and fatigue. All patients were in sinus rhythm and without discernible dependent oedema or ascites. In all the heart was enlarged (cardiothoracic ratio 0.58 to 0.62 ) but without radiographic evidence of pulmonary oedema or pleural effusions in chest radiographs taken standing at rest. Plasma potassium and digoxin concentrations ranged from 3.8 to $5.2 \mathrm{mmol} / \mathrm{l}$ and 1.2 to 2.5 $\mathrm{ng} / \mathrm{ml}$, respectively, in all patients. The purpose of the investigation was explained to each patient and agreed by them and by the hospital ethics committee. 
DESIGN OF THE STUDY

Before the definitive studies were undertaken, patients were familiarised with walking on a treadmill, and the level of such exercise which each could achieve without intolerable breathlessness or fatigue was established. In all instances this was between one and two mph walking on a $5^{\circ}$ incline for four minutes. To overcome the "first dose effect", patients received a single oral dose of $0.5 \mathrm{mg}$ prazosin 24 hours before the study.

The study began with a five minute period of sitting, a similar period of standing at rest, after which the patient walked for four minutes on the treadmill at the predetermined speed and incline. Systemic arterial, pulmonary arterial, and pulmonary artery occluded pressures, heart rate, and cardiac output were measured at minute intervals during the final three minutes of sitting and standing and minute by minute during walking. Systemic and pulmonary arterial blood samples were taken at the same times for estimation of total body oxygen uptake. After the control study, patients were given an oral dose of prazosin $2 \mathrm{mg}$ and the measurements were repeated one hour later.

Treatment was then continued as an outpatient with oral prazosin $2 \mathrm{mg}$ thrice daily in addition to their usual digoxin and frusemide, the dosages of which were maintained constant throughout the 12 weeks of the study in each patient. At the end of this time, haemodynamic studies were repeated in each patient at the same time in the afternoon as in the first study and one hour after the second daily oral dose of $2 \mathrm{mg}$ prazosin.

LABORATORY TECHNIQUES, MEASUREMENTS, AND STATISTICS

Heart rate was measured from the electrocardiogram and systemic arterial pressure through a brachial arterial catheter. Pulmonary vascular pressures were measured through a balloon-tipped thermodilution catheter positioned radiographically so that inflation of the balloon resulted in replacement of the pulmonary artery pressure record by a typical pulmonary wedge pressure tracing. Pressures were externally transduced with strain gauges and recorded together with the heart rate on an ultraviolet recorder. Mean pressures were integrated electronically. Heart rate and pressure measurements were averaged over two respiratory cycles. Cardiac output was measured by thermodilution and automatically computed (Instrumentation Laboratories Computer 601/Recorder 602) using a gas-operated constant-speed injector (OMP Model 3700 ) with $10 \mathrm{ml}$ of dextrose-saline at $0^{\circ} \mathrm{C}$ as indicator. This system was calibrated in vitro; the variance of the measurement in patients at rest was
$5 \cdot 8 \%$. Blood oxygen saturation was measured by haemoreflector and blood oxygen capacity by spectrophotometry as previously detailed. ${ }^{17}$ Total body oxygen uptake was calculated from the Fick equation. Vascular resistances were calculated by conventional means. Plasma potassium concentration was measured on an autoanalyser and plasma digoxin concentration by radioimmunoassay.

Haemodynamic measurements and derived data were averaged during the sitting period. Statistical analysis was by standard two-way analysis of variance, partitioning the variance between drug treatment time and patients.

\section{Results}

STUDY 1: ACUTE ADMINISTRATION OF PRAZOSIN Twelve patients were included in the study. One patient, in whom the pulmonary artery occluded pressure fell to $7 \mathrm{mmHg}$ one hour after $2 \mathrm{mg}$ prazosin, became hypotensive on standing, precluding further study. The results concern the remaining 11 patients.

\section{Before prazosin (Table 1)}

Changing posture from sitting to standing resulted in a significant decrease in the pulmonary vascular pressures without change in any of the other measured or calculated haemodynamic variables. During walking, with the exception of the systemic arterial diastolic pressure, there were progressive increases in all measured haemodynamic variables which followed a linear or quadratic trend. There was a quadratic decrease in the calculated systemic vascular resistance during exercise but no change in the pulmonary vascular resistance.

\section{After prazosin}

Sitting at rest, one hour after $2 \mathrm{mg}$ prazosin, there were significant reductions in systemic and pulmonary vascular pressures and their related resistances compared with control measurements. Total body oxygen uptake, cardiac output, heart rate, and stroke volume were unchanged. On standing, the pulmonary pressures and resistance were further reduced without change in the systemic arterial pressure, cardiac output, heart rate, or stroke volume. During walking at a total body oxygen uptake similar to that before prazosin, the pattern of the haemodynamic response was unchanged, though the absolute values of systemic and pulmonary vascular pressures and the related resistances were all significantly less than in the control study. Heart rate, cardiac output, and stroke volume were not significantly different from the values measured during walking before the drug was given. 


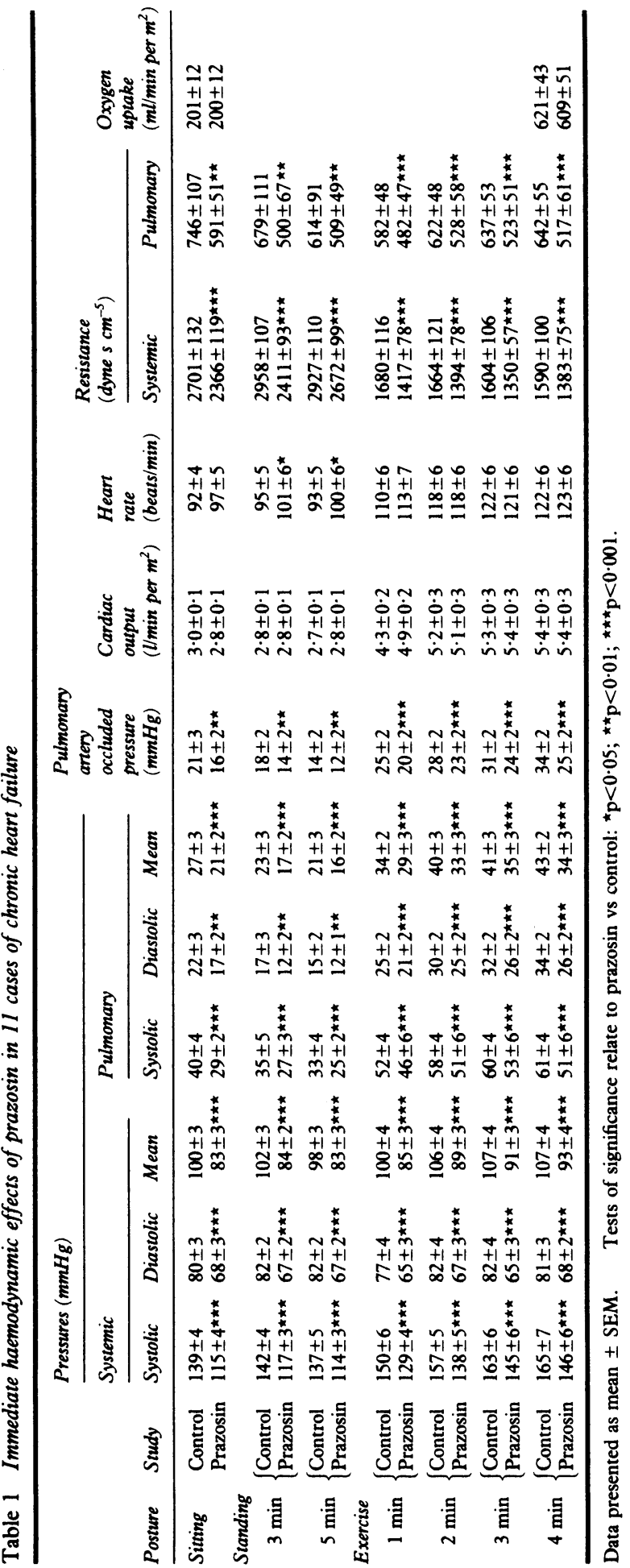


STUDY 2: CHRONIC ADMINISTRATION

Of the original 11 patients completing the acute study, two died and three underwent resection of left ventricular aneurysms for uncontrollable heart failure before the follow-up study. The results, including comparison with the acute studies, therefore concern the remaining six patients. In these six the haemodynamic values in the control and post-prazosin acute studies were not substantially different from those in the original group of 11 patients.

After 12 weeks on prazosin (Fig. 1 and 2; Table 2) Sitting at rest, the systemic arterial pressure was still reduced compared with the pre-prazosin control studies but the reduction was significantly less than that after the first dose of the drug. The average calculated systemic vascular resistance, however, was not significantly different from that of the control study. The reductions in the pulmonary vascular pressures and resistance seen after the first dose of prazosin were absent. There was a small but statistically significant reduction in cardiac output without similar change in heart rate or stroke volume.

On standing there were further small statistically significant reductions in the pulmonary vascular pressures. Systemic arterial pressure, cardiac output, heart rate, and stroke volume were unchanged.

During walking, the total body oxygen uptake and the pattern of change in all haemodynamic variables was similar to that of the two foregoing studies. The final absolute values of systemic arterial pressure and pulmonary artery occluded pressure reached after walking for four minutes were significantly less than those in the control studies but greater than those after the first dose of prazosin. There were no significant differences in heart rate, cardiac output, or stroke volume between the three studies during walking. The reductions in the systemic and pulmonary vascular resistances after the first dose of drug were absent after sustained treatment.

\section{Discussion}

In our patients with severe ischaemic heart failure the immediate and sustained haemodynamic effects of adding prazosin to their diuretic and digoxin treatment, both at rest and during walking, are clearly defined. When first given, the drug rapidly reduced the systemic arterial and pulmonary venous pressures while sitting, standing, and during walking without

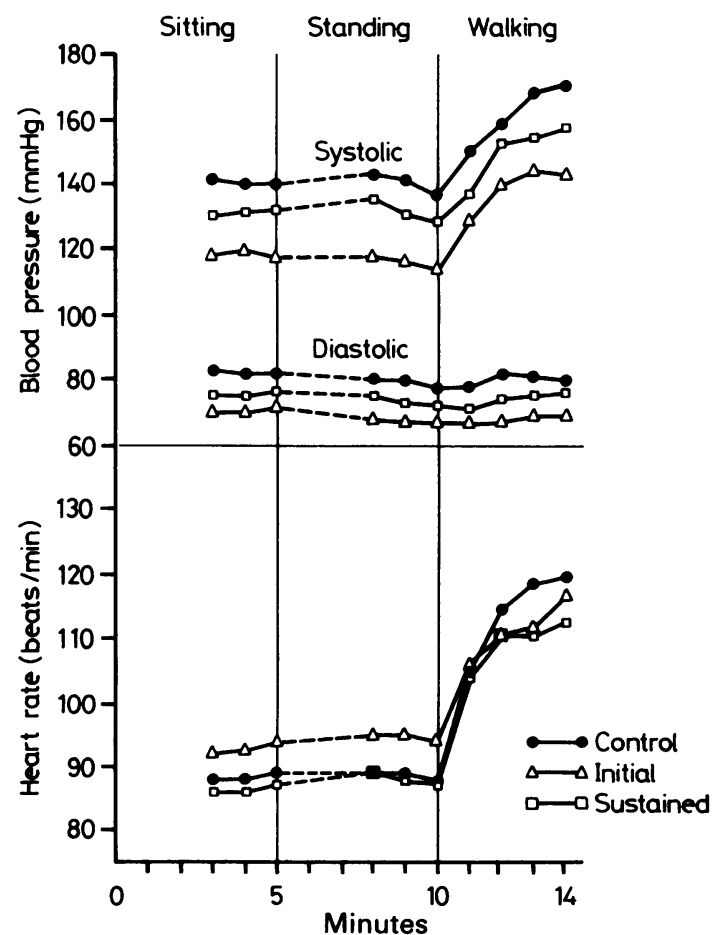

Fig. 1 Immediate and sustained haemodynamic effects of prazosin in six patients in severe ischaemic heart failure. 


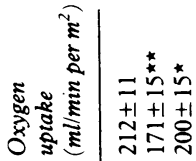

웋주

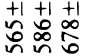

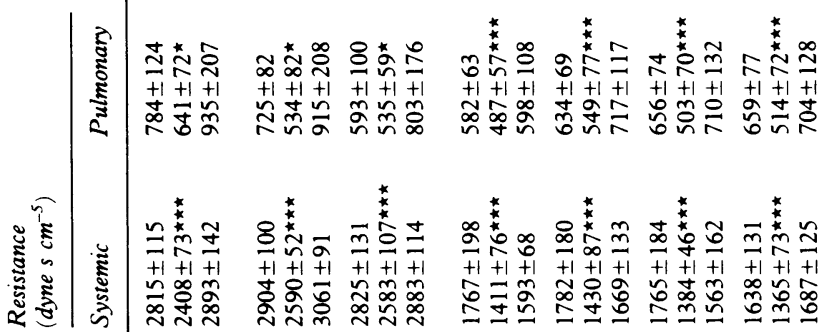

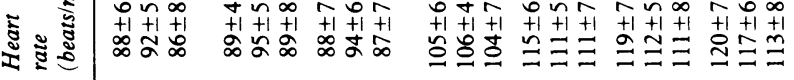

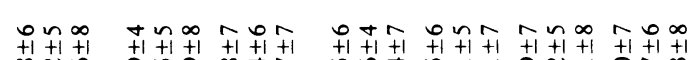

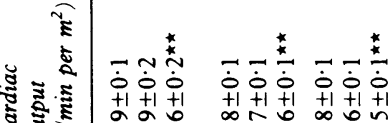
政

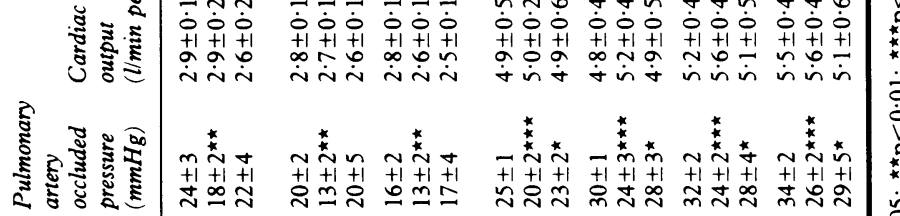

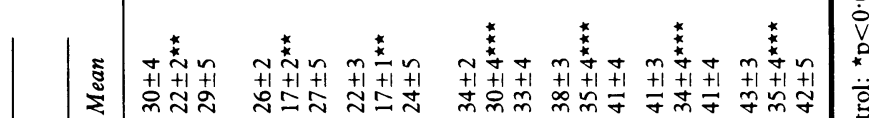

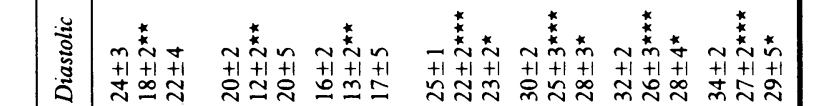

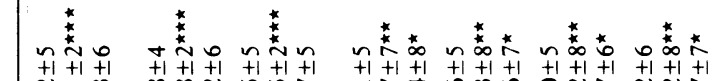

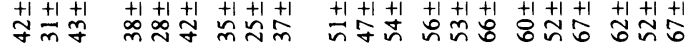

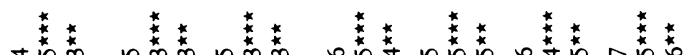

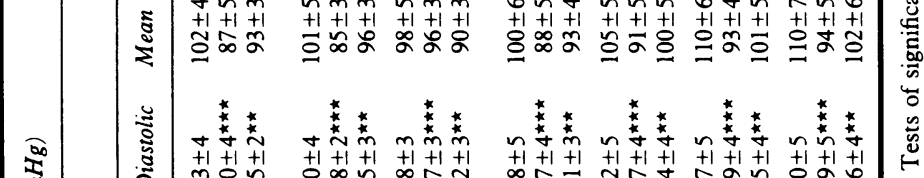

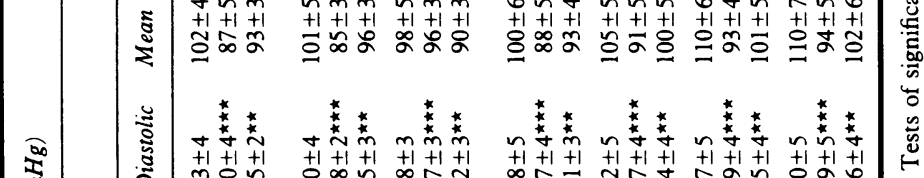

है

密

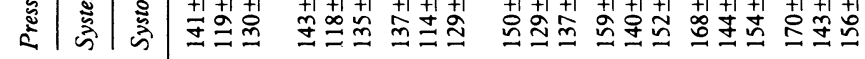


change in the minute or stroke output of the heart. The majority of the reduction in pulmonary venous pressure presumably resulted from increased capacitance of the systemic veins, ${ }^{18}{ }^{19}$ though the substantial reduction in the pulmonary vascular gradient without change in the pulmonary blood flow suggests that an element of pulmonary venodilatation cannot be entirely excluded. The mechanism of the reduction in systemic arterial diastolic pressure after prazosin is more complex and probably involves two haemodynamic mechanisms. Arteriolar dilatation could be expected to result from blockade of alpha $a_{1}$ adrenoceptors in peripheral resistance vessels. The reduction in pulmonary venous pressure could also be expected to reduce the vasoconstriction initiated reflexly by left atrial and pulmonary venous distension. Whatever the exact mechanism, however, the related reduction in aortic impedance, together with the reduction in left heart filling pressure and presumably volume, jointly afford a substantial decrease in left ventricular afterload. It is intriguing, therefore, that such a reduction in afterload, normally a major determinant of cardiac output and the physiological basis on which vasodilators are given, was not associated with any significant increases in output either at rest or during walking in any of our patients. The reason for this is not clear. All our patients were in clinical class III and they all had adequate left ventricular function to allow an increase in cardiac output during exercise. It is possible that the magnitude of the reduction in left ventricular filling pressure after prazosin inhibited an improvement in the output, despite the fact that at all times the filling pressure was substantially greater than normal. It is also possible that the drug was exerting a direct negative inotropic effect on the myocardium. Which of these possibilities contributed to the failure of prazosin to induce an improvement in the cardiac output response to exercise is unknown.

It is an important clinical point that despite the selective blockade of alpha $a_{1}$ adrenoceptors in the peripheral arteries and veins by prazosin, sufficient to result in a fall in sitting blood pressure, this did not prevent the normal increase in diastolic blood pressure when the patients stood up. Neither did it augment the reduction in systemic vascular resistance that normally occurs during exercise. This suggests that postural or exercise hypotension is unlikely in heart failure patients during sustained treatment with prazosin, at least with the doses used in this study.

The majority of other reports are agreed that the pulmonary venous pressure is reduced after a single dose of prazosin in patients in chronic heart failure, but some have claimed that the cardiac output was increased by the drug, both at rest $^{89}$ and during exercise. ${ }^{710}$ These reports were based on studies which differed from ours, however, in the important respect that they were carried out in the supine position whereas our patients were upright, both at rest and during exercise. A vasodilator drug affecting both arterial and venous circulations can be expected to produce substantially different haemodynamic effects in the supine and erect postures. Similarly, bicycle exercise with the legs above heart level also induces larger increases in cardiac output than those resulting from walking. Moreover, there appears to be an inverse relation between the absolute level of cardiac output at rest and its increase after oral prazosin. ${ }^{20}$ Our patients had a somewhat greater cardiac output than those reported in other studies so could not have been expected to show the same magnitude of increase in this variable as claimed by others. These rationalisations may go some way towards explaining the reported differences between the various studies.

Considerable debate has surrounded the possible mechanisms responsible for the attenuation of the effects of prazosin during sustained treatment of patients in chronic heart failure. ${ }^{13-15}$ Our studies not only confirm such attenuation of the haemodynamic effects of the drug at rest, but also during exercise, even after such a relatively short time as 12 weeks of treatment (Fig. 3). The attenuation of the pharmacodynamic activity of prazosin during its sustained administration in patients in heart failure could be the result of a number of factors. Reduction in metabolic degradation of the drug in patients in heart failure results in its increased plasma concentration after a given dose. ${ }^{1621-23}$ Reduced binding of the drug to plasma proteins also results in an increase in the free fraction in the blood. ${ }^{24} 25$ It is conceivable that at these higher plasma concentrations of free prazosin the alpha 1 selectivity of the drug may be lost; this

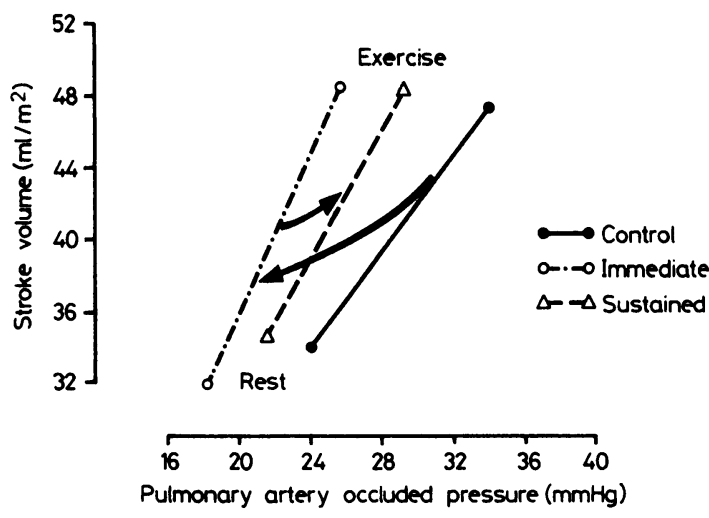

Fig. 3 Left heart function relations before, immediately after, and during the sustained administration of prazosin in six patients with ischaemic heart failure. 
could be expected to result in an increased plasma catecholamine concentration because of blockade of presynaptic alpha $a_{2}$ adrenoceptors in the terminal sympathetic neurone. Such increased plasma concentration of noradrenaline would not only tend to offset the direct vascular effects of prazosin, but could also be expected to stimulate renin secretion with consequent retention of salt and water. It is relevant, therefore, that increased plasma levels of both noradrenaline and renin have been reported during sustained treatment with the drug in heart failure patients. ${ }^{26-28}$ In addition, lower doses of oral prazosin appear to be associated with less attenuation of its haemodynamic effects than higher doses. ${ }^{29-31}$ Moreover, when chronic tolerance has developed the haemodynamic effects of the drug have been restored by increasing the dose of diuretics or aldosterone antagonists. $^{32} 33$

The fragmentary nature of this information precludes definition of the most effective counter to this attenuation of the haemodynamic effects of sustained treatment with prazosin in patients in chronic heart failure. This must await further description of the pharmacokinetic, haemodynamic, and humeral patterns of activity of the drug in patients with various forms of heart failure. Until such information is available, the full potential benefit that prazosin holds for patients with heart failure cannot be realised.

We thank Drs R Ahuja, R Okoli, P S Lee, and R Lochan for their help. The study was supported by grants from Pfizer Research Ltd, the Yorkshire Regional Hospital Board, and the West Riding Research Trust.

\section{References}

1 Majid PA, Sharma B, Taylor SH. Phentolamine for vasodilator treatment of severe heart failure. Lancet 1971; ii: 719-24.

2 Braunwald E. Vasodilator therapy - a physiologic approach to the treatment of heart failure. $N E n g l f M M e d$ 1977; 297: 331-3.

3 Mason DT. Symposium perspective. In: Symposium on vasodilator and inotropic therapy of heart failure. $A m \mathcal{F}$ Med 1978; 65: 101-5.

4 Taylor SH. Pharmacodynamic basis of the use of vasodilators in the treatment of heart failure. Med $\mathcal{F}$ Aust 1980; ii: 18-35.

5 Taylor SH. Vasodilator drugs in the treatment of heart failure. f Cardiovasc Pharmacol 1980; 2, suppl 3: S407-25.

6 Awan NA, Miller RR, De Maria AN, Maxwell KS, Neumann A, Mason DT. Efficacy of ambulatory systemic vasodilator therapy with oral prazosin in chronic refractory heart failure: concomitant relief of pulmonary congestion and elevation of pump output demonstrated by improvements in symptomatology, exercise tolerance, hemodynamics and echocardiography. Circulation 1977; 56: 346-54.

7 Awan NA, Miller RR, Miller MP, Specht K, Vera Z, Mason DT. Clinical pharmacology and therapeutic application of prazosin in acute and chronic refractory congestive heart failure. Balanced systemic venous and arterial dilation improving pulmonary congestion and cardiac output. Am 7 Med 1978; 65: 146-54.

8 Miller RR, Awan NA, Maxwell KS, Mason DT. Sustained reduction of cardiac impedence and pre-load in congestive heart failure with the anti-hypertensive vasodilator prazosin. $N$ Engl f Med 1977; 297: 303-7.

9 Reuben SR, Blake P, Gale EV. The acute haemodynamic effects of prazosin in congestive heart failure. In: Rawlins MD, Geyer G, Bleifeld W, eds. European prazosin symposium. Amsterdam \& Oxford: Excerpta Medica, 1979: $141-6$.

10 Hutton I, Vallance BD, McLauchlan J, et al. Prazosin in chronic congestive cardiac failure - an acute haemodynamic study. In: Rawlins MD, Geyer G, Bleifeld W, eds. European prazosin symposium. Amsterdam \& Oxford: Excerpta Medica, 1979: 135-40.

11 Aronow WS, Lurie M, Turbow M, Whittaker K, Van Camp S, Hughes D. Effect of prazosin vs. placebo on chronic left ventricular heart failure. Circulation 1979; 59: 344-50.

12 Colucci WS, Wynne J, Holman BL, Braunwald E. Long-term therapy of heart failure with prazosin: a randomized double-blind trial. Am $\mathcal{F}$ Cardiol 1980; 45: 337-44.

13 Arnold SB, Williams RL, Ports TA, et al. Attenuation of prazosin effect on cardiac output in chronic heart failure. Ann Intern Med 1979; 91: 345-9.

14 Packer M, Meller J, Gorlin R, Herman MV. Hemodynamic and clinical tachyphylaxis to prazosin-mediated afterload reduction in severe chronic congestive heart failure. Circulation 1979; 59: 531-9.

15 Elkayam U, Lejemtel TH, Mathur M, et al. Marked early attenuation of hemodynamic effects of oral prazosin therapy in chronic congestive heart failure. Am $\mathcal{F}$ Cardiol 1979; 44: 540-5.

16 Silke B, Lakhani ZM, Taylor SH. Pharmacokinetic and pharmacodynamic studies with prazosin in chronic heart failure. 7 Cardiovasc Pharmacol 1981; 3: 329-35.

17 Sharma B, Majid PA, Meeran MK, Whitaker W, Taylor $\mathrm{SH}$. Clinical, electrocardiographic and haemodynamic effects of digitalis (Ouabain) in angina pectoris. Br Heart f 1972; 34: 631-7.

18 Awan NA, Miller RR, Maxwell K, Mason DT. Effects of prazosin on forearm resistance and capacitance vessels. Clin Pharmacol Ther 1977; 22: 79-84.

19 Collier JG, Lorge RE, Robinson BF. Comparison of effects of Tolmesoxide (RX 7 1107), diazoxide, hydrallazine, prazosin, glyceryl trinitrate and sodium nitroprusside on forearm arteries and dorsal hand veins of man. Br F Clin Pharmacol 1978; 5: 35-44.

20 Taylor CR, Baird JRC, Blackburn KJ, et al. Pharmacology and clinical efficacy of some of the newer agents for the treatment of heart failure. Am Heart $\mathcal{F} 1981$; 102: 515-32. 
21 Jaillon P, Rubin P, Yee Y-G, et al. Influence of congestive heart failure on prazosin kinetics. Clin Pharmacol Ther 1979; 25: 790-4.

22 Baughman RA Jr, Arnold S, Benet LZ, Lin ET, Chatterjee $\mathrm{K}$, Williams RL. Altered prazosin pharmacokinetics in congestive heart failure. Eur. $\mathcal{F}$ Clin Pharmacol 1980; 17: 425-8.

23 Jaillon P. Clinical pharmacokinetics of prazosin. Clin Pharmacokinet 1980; 5: 365-76.

24 Rubin P, Blasckhe T. Prazosin protein binding in health and disease. Br F Clin Pharmacol 1980; 9: 177-82.

25 Pierpont GL, Franciosa JA, Cohn JN. Effect of prazosin on renal function in congestive heart failure. Clin Pharmacol Ther 1980; 28: 335-9.

26 Colucci WS, Williams GH, Braunwald E. Increased plasma norepinephrine levels during prazosin therapy for severe congestive heart failure. Ann Intern Med 1980; 93: 452-3.

27 Stein L, Henry DP, Foster PR, Statza J. Paradoxical increase in norepinephrine during beneficial prazosin therapy for heart failure (abstract). Circulation 1979; 60: suppl II-129.

28 Aronow WS, Lurie $M$, Turbow $M$, Whittaker $\mathrm{K}$, Van Camp S, Hughes D. Effect of prazosin vs. placebo on chronic left ventricular heart failure. Circulation 1979; 59: 344-50.

29 Colucci WS, Wynne J, Holman BL, Braunwald E. Long-term therapy of heart failure with prazosin: a randomised double-blind trial. Am $\mathcal{F}$ Cardiol 1980; 45: 337-44.

30 Harper RW, Claxton H, Middlebrook K, Anderson S, Pitt A. The acute and chronic haemodynamic effects of prazosin in severe congestive cardiac failure. Med $\mathcal{F}$ Aust 1980; suppl: 36-8.

31 Awan NA, Evenson MK, Needham KE, Mason DT. Management of refractory congestive heart failure with prazosin. Am Heart $\mathcal{F} 1981$; 102: 626-34.

32 Awan NA, Amsterdam EA, Mason DT. Impedance reduction in severe left ventricular failure. Cardiovasc Med 1979; 4: 933-57.

33 Colucci WS, Williams GH, Braunwald E. Clinical, haemodynamic and neuroendocrine effects of chronic prazosin therapy for congestive heart failure. Am Heart $\mathcal{F}$ 1981; 102: 615-21.

Requests for reprints to Dr S H Taylor, Department of Medical Cardiology, The General Infirmary, Great George Street, Leeds LS1 3EX. 